\title{
Current Methods for Extraction and Concentration of Enteric Viruses from Fresh Fruit and Vegetables: Towards International Standards
}

\author{
Luciana Croci • Eric Dubois • Nigel Cook • \\ Dario de Medici • Anna Charlotte Schultz • \\ Bernard China • Saskia A. Rutjes • Jeffrey Hoorfar • \\ Wim H. M. Van der Poel
}

Received: 7 December 2007 / Accepted: 27 February 2008 / Published online: 5 April 2008

(C) The Author(s) 2008

\begin{abstract}
Virus-contaminated soft fruits or vegetables are increasingly identified as causes of foodborne viral illness. Noroviruses and hepatitis A virus are the most common pathogens in viral infections transmitted by these kinds of foods. To improve microbiological detection and monitoring and to increase insights into the contribution of fruits and vegetables to foodborne viral transmission, sensitive, reliable, and standardized methods are needed. More studies on virus detection methods for foods are being published, but validated consensus protocols are not yet available. In this paper, different methodologies are reviewed critically. The use of process controls and internal amplification controls is discussed.
\end{abstract}

Keywords Extraction - Concentration PCR - Vegetables · Fruit $\cdot$ Norovirus $\cdot$ Hepatitis A Virus

\footnotetext{
L. Croci $\cdot$ D. de Medici

Istituto Superiore di Sanità,

Viale Regina Elena 299,

00161 Rome, Italy

E. Dubois

Agence Française de Sécurité Sanitaire des Aliments,

23 Avenue du Général de Gaulle,

94706 Maisons-Alfort, France

N. Cook

Central Science Laboratory,

Sand Hutton,

York YO41 1LZ, UK

A. C. Schultz $\cdot$ J. Hoorfar

Danish Institute for Food and Veterinary Research,

Moerkhoej Bygade 19, DK-2860 Soeborg,

Copenhagen, Denmark
}

\section{Introduction}

Soft fruits and vegetables consumed raw are sources of fairly large and growing numbers of viral infections in various countries (Reid and Robinson 1987; Seymour and Appleton 2001). Among the foodborne enteric viruses, noroviruses (NoVs) are the most common cause of illness (Koopmans and Duizer 2004), but other viruses such as hepatitis A and $\mathrm{E}$ virus (HAV and HEV), rotavirus, and enterovirus are implicated in foodborne outbreaks as well (Dalton et al. 1996; Koff 1998; Matsumoto et al. 1989; Svensson 2000; Tei et al. 2003). Frozen raspberries have been linked to at least two outbreaks of HAV (Reid and Robinson 1987; Ramsay and Upton 1989) and two outbreaks of caliciviruses (Le Guyader et al. 2004a; Falkenhorst et al. 2005). In one of these outbreaks, the same batch of raspberries caused a series

B. China

Food Sciences Department, Faculty of Veterinary Medicine,

University of Liege,

Sart-Tilman,

4000 Liege, Belgium

S. A. Rutjes

Laboratory for Zoonoses and Environmental Microbiology,

RIVM,

Antonie van Leeuwenhoeklaan 9,

3720 BA Bilthoven, The Netherlands

W. H. M. Van der Poel $(\bowtie)$

Division Virology,

Central Veterinary Institute of Wageningen University Research,

Edelhertweg 14,

8219 PH Lelystad, The Netherlands

e-mail: wim.vanderpoel@wur.nl 
of sub-outbreaks in which multiple strains of $\mathrm{NoV}$ infected 1,100 people in Denmark during summer 2005 (Falkenhorst et al. 2005). In 2003, caliciviruses were detected in different lots of Serbian frozen raspberries as reported in the EU Rapid Alert Systems for food and feed. At least three outbreaks of hepatitis A have been attributed to frozen strawberries, and lettuce and raw blueberries were associated with an outbreak of hepatitis A in New Zealand (Calder et al. 2003). In September 2003, during a big outbreak of hepatitis A, which occurred in the USA and involved approximately 555 persons, three people died. Preliminary analysis of a case-control study implicated raw green onions as the source of the infection (Anonymous 2003; Wang and Moran 2004). In the UK, $15.7 \%$ of all cases of infections linked with salad and fruit consumption were correlated with NoV contamination. These products, which are grown for relatively brief periods and are normally eaten raw (e.g., green salad), are considered particularly hazardous to consumers (Rosenblum et al. 1990; Pebody et al. 1998). Contamination can occur during growth of vegetables as a result of the use of contaminated fertilizers or wastewater (Steele and Odumeru 2004). It is possible that enteric viruses in soil can be transferred to the whole plant through damaged roots; however, this way of contaminating fruits and vegetables was inefficient and has been observed only during experiments performed with large numbers of virus particles (Oron et al. 1995). When account is taken of the ban on the use of sewage sludge as a fertilizer for production of fruits and vegetables, such internal contamination should not occur naturally. On the other hand, the surface of fruits and vegetables may well be exposed to fecal contamination during irrigation with contaminated water (Ward et al. 1982). During the preparation and distribution of these food types, viruses can be transmitted by infected food handlers especially when hygienic norms are not followed (Dalton et al. 1996; Dalton 1997). Some studies have shown that approximately $9.2 \%$ of infectious virus particles on contaminated hands can be transferred to lettuce when this is handled (Bidawid et al. 2002a). Moreover, these products are processed without the inclusion of a step for inactivation or removal of bacteria and viruses. To improve microbiological monitoring of food quality and assess the true role of food in viral transmission, standardized methods need to be developed for use in reference laboratories and for the monitoring of foodstuffs.

Various studies have dealt with the development of standardized methods for detection of enteric viruses in foods. Some of these studies were carried out as part of European projects such as SEAFOODplus (www.seafoodplus. org), which included detection of viruses in mussels. As regards the standardization of methods for detection of viruses in vegetables and fruit, the only comparative study that has been reported was carried out on lettuce within the
European project "Foodborne viruses in Europe" (Le Guyader et al. 2004b).

However, a single, detailed, and internationally validated protocol may not be suitable for all fruits and vegetables. Rather, various modifications of a basic protocol for groups of fruit and vegetables are thought to be needed to take account of the differences in the morphology and hydrophobic interactions of fruit and vegetable surfaces, differences in tissue compositions (that affect the amounts of PCR inhibitory substances in, the $\mathrm{pH}$ of, and other qualities of, samples from fruits and vegetables), and the processing conditions to which the produce were subjected before they were sampled (Dalton 1997; Cliver et al. 1983; Gulati et al. 2001; Kurdziel et al. 2001; Allwood et al. 2004).

In this paper, current methodologies are reviewed and various strategies are proposed for the choice of controls for procedures for detection of viruses. The use of an internal amplification control (IAC), which is necessary for international standardization, is discussed.

\section{Virus Detection}

Before molecular methods were common use, methods for detecting human enteric viruses in foods were based on the inoculation of suitable food extracts into cell cultures. However, because some enteric viruses cannot propagate in cell culture, they are generally detected using the molecular technique of reverse transcription-PCR (RT-PCR) which involves the amplification of conserved regions of the microorganisms' genomes. The technique is extremely sensitive and specific but it is unable to distinguish between infectious and non-infectious virus particles (Richards 1999). Also, the amplification of the genetic material can often be inhibited by substances that are present in the foods and therefore the removal or inactivation of potential inhibitors is a very important step in this methodology (Atmar et al. 1995; Kreader 1996).

Most methods are designed to concentrate and purify viruses and remove inhibitors before performing the RTPCR. For these purposes, multi-step elution and extraction procedures are employed using a combination of several reagents. Using this approach, significant progress has been made in the detection of enteric viruses in shellfish (Le Guyader et al. 1994; Lees et al. 1995; De Medici et al. 1998; Croci et al. 1999, 2000; Le Guyader et al. 2000; De Medici et al. 2001, 2004). But much still needs to be done before protocols for use with shellfish are suitable for other foods.

Typically, a method for detection of viruses in food involves the three different steps of: (1) elution and clarification of the virus from the foodstuff, (2) concentration of the virus particles, and (3) nucleic acid extraction 
and detection. Various strategies have been proposed for the performance of each step.

\section{Virus Elution and Clarification}

Detection of virus in fruits and vegetables starts with the elution of the virus particles from the surface of the product. Sadovski et al. (1978) published a paper on the effects of manipulations of the drip irrigation procedures on contamination of crops by bacteria and viruses from effluent. For this purpose, cucumbers (Cucumis sativum) were experimentally contaminated with poliovirus. The virus was eluted from samples by two consecutive treatments with $1,000 \mathrm{ml}$ of $0.85 \%$ sodium chloride in $0.02 \mathrm{M}$ phosphate buffer, $\mathrm{pH}$ 8.0. Some authors have proposed only a vigorous washing with distilled water, followed by centrifugation at $2,000 \times g$ for $20 \mathrm{~min}$, for elution of HAV and rotavirus from lettuce (Latuca sativa) and removing heavy contaminating material from the eluate (Hernandez et al. 1997). However, many other eluting buffers have been used such as phosphate buffer, $\mathrm{pH} 7.6$, to elute HAV from lettuce and fresh strawberries (Bidawid et al. 2000b) and calicivirus from frozen strawberries (Ponka et al. 1999); 1M sodium bicarbonate alone (Kurdziel et al. 2001 ) or with the addition of $1 \%$ soya protein (Rzeżutka et al. 2005) for elution of enteric viruses from soft fruit and salad; and 3\% beef extract buffer, $\mathrm{pH} 9.5$, for elution of HAV from fresh produce such as lettuce, fennel, and carrot (Croci et al. 2002). Acidic fruits such as raspberries can reduce the $\mathrm{pH}$ of the "eluant" or "extractant" during the elution step, which may lead to the $\mathrm{pH}$ falling below neutrality, with reduction of the elution capacity and consequent reduction of the detection sensitivity.

\section{Eluant Conditions}

Dubois et al. (2002) proposed a protocol that includes washing the fruit or vegetable surface with a basic buffer (pH 7.4 to 9.5) supplemented with a salt (100mM Tris$\mathrm{HCl})$, an amino acid (50mM glycine), and protein (3\% beef extract). The proposed washing fluid breaks the electrostatic and hydrophobic interactions between fruit or vegetable surfaces and viruses. The supplementing of the buffer with Tris favors the elution of virus particles from acidic berries and provides a satisfactory medium when the eluate is to be used in RT-PCR, but it decreases viral infectivity. To limit the decrease in viral infectivity caused by the solution, it was supplemented with $50 \mathrm{mM} \mathrm{MgCl}$. Previous studies had shown that enteric viruses are more resistant to inactivation in the presence of $\mathrm{MgCl}_{2}$ (Parry and Mortimer 1984). Pectinase should also be added to prevent jelly formation (Rzeżutka et al. 2005; Dubois et al. 2002; Rzeżutka et al. 2006). Le Guyader et al. (2004b) compared five methods
(A-E) for the detection of enteroviruses, canine caliciviruses, and NoVs from spiked lettuce. Four of the methods included the use of a different elution buffer. The buffers used were: phosphate-buffered saline and Vertrel solution (1,1,1,2,3,4,4,5,5,5-decafluoropentane) (methods A and D), $3 \%$ beef extract, $\mathrm{pH} 9.5$ (method B), glycine-buffered saline, $\mathrm{NaCl}$ plus $0.05 \mathrm{M}$ glycine, $\mathrm{pH} 9.5$ (method $\mathrm{C})$, and glycine buffer, $\mathrm{pH} 8.5$ (method E). For method $\mathrm{C}$, the addition of a cationic agent CatFloc TL (polydiallyldimethylammonium chloride) and a chloroform-butanol (1:1) mixture to enhance the flocculation and clarification of the eluate was proposed. The data suggested that methods $\mathrm{C}$ and $\mathrm{E}$ provided better results, irrespective of the differences between subsequent concentration steps.

\section{Clarification}

After elution, it is necessary to remove food particles from the eluate containing the viruses in suspension. This clarification should be performed at high $\mathrm{pH}$ to prevent the adsorption of viruses to the fruit or vegetable matter. Frequently, low speed centrifugation at $14,000 \times g$ or below has been used to clarify the eluate. The pellet containing fruit or vegetable matter could then be discarded while viruses remained in the aqueous phase. Filtration through large porosity filters, previously treated for non-adsorption of viruses, has also been used to remove food particles. Pectinase can be added after clarification to prevent jelly formation during neutralizing of the eluate (Rzeżutka et al. 2005; Dubois et al. 2002; Rzeżutka et al. 2006). Without the addition of pectinase, jellies can form in eluates containing juices from soft fruits such as raspberries and frozen fruits.

\section{Concentration of Virus Particles}

If contaminated at all, foods are likely to contain very low levels of enteric viruses. Considering this and the low infectious dose of viruses, the concentration step is very important for realistic detection of enteric viruses in food products.

Various strategies have been proposed for the concentration of viruses. Virus concentration methods always have to be adapted to be compatible with the eluant used and the type of food that is being analyzed. For example, juices released from soft fruits might interfere with virus concentration through filtration by clogging the filters. In such a case, precipitation of viruses would be preferable. Viruses can be precipitated by the addition of polyethylene glycol (PEG) to the clarified eluate, which is a compound that reduces the solubility of macromolecules (Lewis and Metcalf 1988).

Salad vegetables are more resistant to disruption by washing treatments than are soft fruits. Viruses in clarified 
eluates from salad vegetables can therefore be concentrated by filtration, which is more rapid than concentration by precipitation. The viruses adsorbed on membrane or cartridge filters can be eluted with the same eluants as used with fruit and vegetable surfaces, but with smaller volumes of eluate.

Ultracentrifugation at $100,000 \times g$ can be used to pellet viruses. This last method requires expensive equipment and can be used only with eluates free of vegetable matter that were obtained from hard fruits or vegetables. Recently, this method of concentration was adapted for use with eluates from fresh raspberries (Rzeżutka et al. 2005; Rzeżutka 2006). Sadovski et al. (1978) performed virus concentration in the following two stages: first, the viruses were absorbed onto $0.45-\mathrm{nm}$ Cox filters and eluted by washing the filter three times with $30 \mathrm{ml}$ of $3 \%$ beef extract, $\mathrm{pH} 9.0$; then, the three washings were pooled and reconcentrated by organic flocculation (Katzenelson et al. 1976). Ward et al. (1982) adapted the Sadovski method for use with large sample sizes of vegetables. To determine the efficiency of virus recovery by this method, poliovirus was seeded onto cabbage, celery, spinach, and lettuce. After elution of samples with 21 of phosphate buffer, $\mathrm{pH} 9.0$ at $4 \mathrm{C}$, the eluate was clarified by filtration through glass wool and glass fiber filters. A preliminary study had shown that the efficiency of virus recovery on such filters was almost $100 \%$. The adsorbed viruses were eluted by washing the filters twice with $3 \%$ beef extract, $\mathrm{pH}$ 9.0. The recovery of viruses was $71 \%$.

Gilgen et al. (1977) studied the detection of enterovirus, rotavirus, $\mathrm{HAV}$, and small round structured viruses in water samples. In this paper, concentration was achieved by a three-phase isolation procedure that included filtration of eluate through a positively charged nylon membrane ultrafilter and cleanup of the viral RNA with a silica-based membrane. Other authors adopted the adsorption of viruses on electronegative or electropositive filters after elution with very similar buffers (containing $1 \%$ or $3 \%$ of beef extract at pH 9.0 or 9.5) (Bidawid et al. 2000b; Dubois et al. 2002). The percentages of recovery of enteric viruses can be variable depending on the method and the vegetable used, e.g., between $36 \%$ and $74 \%$ using filtration of elution buffer used to rinse vegetables artificially contaminated with poliovirus and adenovirus (Ward et al. 1982), between $2 \%$ and $70 \%$ of HAV that were recovered by elution and PEG precipitation with lettuce (Sair et al. 2002), and around $20 \%$ with frozen raspberries (Dubois et al. 2006). A rapid method for the concentration of enteric viruses by filtration was recently validated by an intralaboratory study (Dubois et al. 2006). The method was able to recover $18 \%$ of poliovirus, $64 \%$ of $\mathrm{HAV}$, and $29 \%$ of F-RNA-specific bacteriophages with no significant interfering effects of salad vegetables being observed when the viruses were enumerated by plaque assay or double agar layer method.

\section{Centrifugation}

Centrifugation-based procedures for extraction of viruses from soft fruit and salad vegetables have been developed by Cook and co-workers (Rzeżutka et al. 2005, 2006). These procedures avoid the use of filtration or virus flocculation by removing food debris by centrifugation then concentrating virus particles through sedimentation by ultracentrifugation. Initial details of the methods were published by Kurdziel et al. (2001). Various soft fruits and salad vegetables were artificially contaminated with poliovirus, then stomached or pulsified with $1 \mathrm{M}$ sodium bicarbonate to facilitate removal of viruses from the vegetable surfaces. After decanting, the liquid was centrifuged at $28,000 \times g$ for $30 \mathrm{~min}$ to remove food solids. Removal of solids was assisted by flocculation with CatFloc TL (Kostenbader and Cliver 1981). Viruses were sedimented at $240,000 \times g$ for $1 \mathrm{~h}$ and resuspended in a $500-\mu 1$ volume of cell culture medium. Infectious polioviruses were enumerated before contamination of, and after extraction from, the produce to determine the efficiency of recovery. This was $50 \%$ for lettuce, $20 \%$ for green onion, and $25 \%$ for white cabbage. The recovery efficiency was between $5 \%$ and $65 \%$ for strawberries and between $4 \%$ and $6 \%$ for raspberries, the variability probably due to the nature of the pellet after ultracentrifugation, which was quite gelatinous and difficult to resuspend. The methods were useful for studies of virus survival (Kurdziel et al. 2001), but further development was considered necessary at least for the soft fruit before the centrifugation-based approach was applicable for routine analysis of produce. Rzeżutka et al. $(2005,2006)$ refined the centrifugation-based method for extraction of viruses from raspberries and strawberries. Soya protein powder was incorporated in the alkaline extractant to facilitate desorption of virus particles from surfaces. Instead of stomaching the fruits, they were gently rolled for $15 \mathrm{~min}$ to facilitate removal of virus from the surfaces without producing too much debris. Also, pectinase was added prior to the centrifugation step to produce a smaller and more easily resuspendable pellet after ultracentrifugation. The ultracentrifugation time was increased to $2 \mathrm{~h}$, as this was found to increase recovery. Using infectious poliovirus, the efficiency of recovery was determined to be approximately $40 \%$ (Rzeżutka et al. 2006). Recovery of NoV from raspberries was estimated by diluting the suspensions used to contaminate the fruit and the extracts, extracting nucleic acids, and applying an RT-PCR assay. Comparison between the end points of the NoV RT-PCR signals indicated that at least $10 \%$ of the virus particles were being recovered (Rzeżutka et al. 2005). The sensitivity of detection of HAV in raspberries and strawberries was determined by comparing the number of RT-PCR units detectable in the extract with the number in the contaminating suspension; the method 
(extraction+RT-PCR) was shown to be able to detect $10^{4}$ RT-PCR units HAV in $90 \mathrm{~g}$ fresh strawberries and $10^{3}$ RTPCR units HAV in $60 \mathrm{~g}$ fresh raspberries. The limiting factors for the efficiency of recovery were considered to be the volume of fruit extract used for nucleic acid extraction and the volume of nucleic acid extract used in the RT-PCR. If these could be increased, then it could be possible to increase recovery efficiency by approximately $2 \operatorname{logs}$ (Rzeżutka et al. 2006).

\section{Ultrafiltration}

Another concentration method proposed by various authors is ultrafiltration, in which virus is entrapped in a sample because of its molecular size rather than by particle charge. Pores in the membrane, varying from 10 to $100 \mathrm{kDa}$, permit passage of liquids and low molecular mass particles in solution and exclude viruses and macromolecules. Ultrafiltration has been described for the concentration of viruses from several foods including fruits and vegetables (Le Guyader et al. 2004b; Finance et al. 1981; Kostenbader and Cliver 1981; Rutjes et al. 2005). Release of virus particles from food surfaces prior to ultrafiltration is achieved by using either demineralized water adjusted to $\mathrm{pH} 9.0$ or a 0.05 to $0.09 \mathrm{M}$ glycine-containing elution buffer $(\mathrm{pH} 8.5$ to 9.5 ) and is generally followed by a clarification step using centrifugation. Flocculants might be added to facilitate clarification (Kostenbader and Cliver 1981) and pretreatment of the membranes has been described to positively affect virus recoveries (Berman et al. 1980). Where in the past mainly expensive filter holders with magnetic stirrers were needed to perform ultrafiltration under high pressure, nowadays, several companies provide ultrafiltration spin columns or microconcentrators which are capable of concentrating volumes varying from less than 1 to $80 \mathrm{ml}$. Depending on the type of microconcentrator, volumes can be reduced to $25-200 \mu l$. Le Guyader et al. (2004b) described that, by eluting of viruses in $5 \mathrm{ml}$ of glycine buffer ( $\mathrm{pH}$ 8.5) from $10 \mathrm{~g}$ of artificially contaminated lettuce followed by concentration of the eluate by ultrafiltration, no co-isolation of RT-PCR inhibitors was observed (Rutjes et al. 2005). However, recoveries of calicivirus PCR-detectable units seeded into the eluate appeared to be no more than $0.1 \%$ to $1 \%$, depending on the RNA extraction method (Rutjes et al. 2005). Ultrafiltration recoveries of viable viruses from lettuce as determined by a cell culture plaque assay resulted in much higher recoveries (Kostenbader and Cliver 1981). This large difference in detected recoveries might be explained by the fact that RT-PCR does not only detect viable viruses but defective particles as well.

Those defective particles can pass through the filter, leading to lower comparative recoveries when they are determined by infectivity assay. To demonstrate, the ratio between infectious enterovirus and enterovirus PCR-detectable units determined in water concentrated by negative membrane filtration and ultrafiltration ranged from 70 to 50,000 (Rutjes et al. 2005).

\section{Secondary Purification}

At the end of the sample treatment, a secondary purification may be performed to remove interfering substances previously co-purified with viral particles or to reduce again the final volume of viral concentrates (Ward et al. 1982; Bidawid et al. 2000b; Sair et al. 2002; Dubois et al. 2006; Leggitt and Jaykus 2000). In Table 1, the principal steps of enteric virus purification and concentration methods from different kinds of food, particularly lettuce and fruit, published by various authors, are depicted.

\section{RNA Extraction}

The capacity of an extraction method to obtain a nucleic acid sample as pure as possible is a particularly important step, especially for enteric RNA viruses for which a reverse transcription stage is necessary. Indeed, the high susceptibility of reverse transcriptase to inhibitory substances is a major limiting factor in molecular biological methods (Wilde et al. 1990). Sair et al. (2002) showed that detection of viruses in lettuce samples was consistently less sensitive than in hamburger. This may be due in part to residual inhibitory compounds that continue to be associated with plant food matrices. A lot of methods have been proposed for extracting viral RNA and simultaneously reducing the level of inhibitors (Sair et al. 2002; Butot et al. 2007). When choosing an extraction technique to use for routine testing of a large number of samples, it is important to consider simplicity of use (with the possibility of automatization, rapidity of execution, and costs) (Rutjes et al. 2006). The least expensive methods are "in-house" techniques but they are difficult to automatize, while commercial techniques are more expensive but allow simultaneous extraction of RNA from different samples. The combination of new sophisticated and expensive nucleic acid robots to extract RNA from different matrices allows increased numbers of samples for each cycle of extraction. All RNA extraction methods from food matrices require multiple steps involving the use of reagents such as guanidinium isothiocyanate, cetyltrimethylammonium bromide (CTAB), phenol-chloroform sephadex, chelex, etc. In general, chemical processes only deal with a single category of inhibitors; chelex or sephadex allow salt and small proteins to be effectively eliminated (De Leon et al. 1992; Straub et al. 1994), while CTAB has made it possible to eliminate polysaccharides (Boom et al. 1990). Of the "home-made" methods, the method proposed by Boom et al. (1990) or Afzal and Minor (1994) has been reported in different 


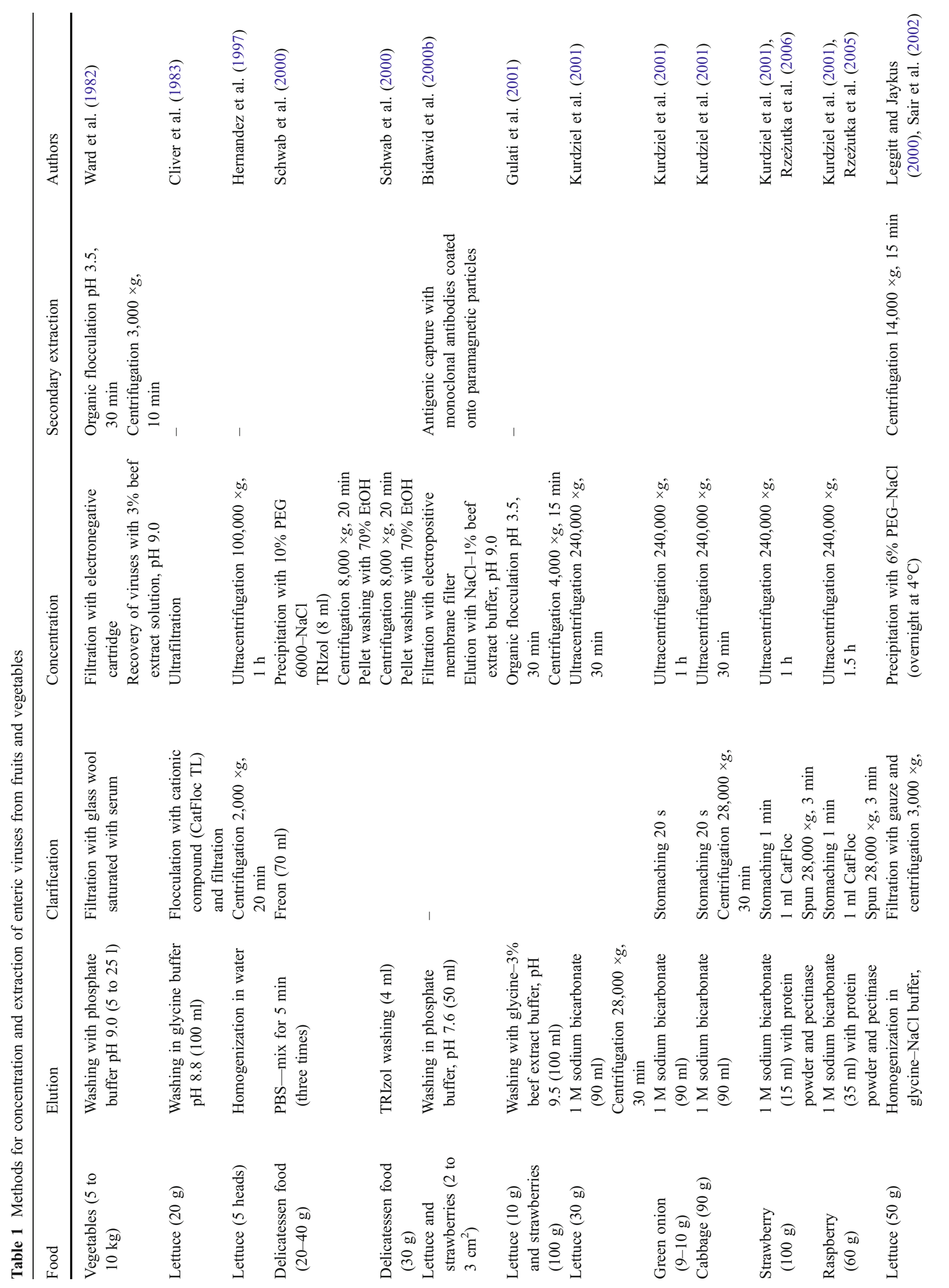




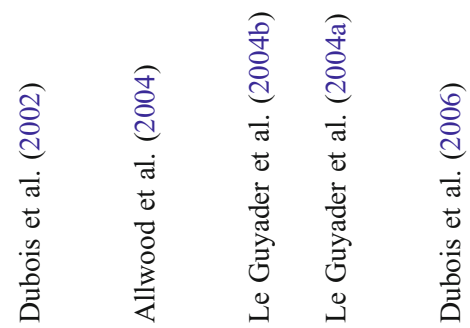

papers to be useful for extraction and purification of viral RNA from vegetables and other food (Croci et al. 2002; Leggitt and Jaykus 2000; Jean et al. 2004). In contrast to chemical processes, viral immunocapture methods are more efficient since they specifically isolate the viruses from the different inhibitory substances present in the sample (De Serres et al. 1999; Kobayashi et al. 2004).

RNA Amplification and Detection

The sensitivity and specificity of the RT-PCR amplification methods depend, in large parts, on primer selection. RTPCR is currently the most widely used diagnostic assay for enteric viruses. Different authors have demonstrated that a single round PCR may not be sensitive enough to detect enteric viruses in food because of the possible low numbers present (De Medici et al. 1998, 2004; Formiga-Cruz et al. 2005), and thus only using a second round of amplification might lead to detection of the virus. In particular, DNA amplification sensitivity and specificity using RT-PCR depends, to a large degree, on the selection of primers and probes. To accommodate this, efforts are being made within various EU projects, between reference laboratories and within the European Committee for Standardization/Technical Committee/Working Group 6/Task Group 4 on virus detection in foods (CEN/TC275/WG6/TAG4), to standardize RT-PCR-based protocols. The introduction of automatic amplification technology such as RT-PCR and nucleic acid sequence-based amplification (NASBA) has significantly improved and simplified the detection of viral nucleic acids. NASBA is an isothermal nucleic acid amplification method that amplifies an RNA template without a separate reverse transcription step (Cook 2003). The NASBA approach has been applied to the detection of enteric viruses such as the genogroup I and genogroup II NoVs (Moore et al. 2004) and HAV (Jean et al. 2001).

\section{Quality Controls}

Extraction and reverse transcription are critical steps for the detection of RNA viruses in foods. In order to achieve reliable and sensitive results, it is important to take into account the extraction efficiency, avoidance of contamination during the whole process, optimal RT-PCR conditions, and adequate primer sets (Sair et al. 2002; Nishida et al. 2003; Vinje et al. 2003). The consequence of a false negative result may be an undetected contamination, whereas false positive results might arise from laboratory contamination, especially when performing two subsequent rounds of PCR or nested PCR. Therefore, to avoid false negative and false positive PCR results, appropriate controls need to be included. 
Vegetables and fruits may contain substances that could inhibit the individual RT and PCR reactions. Many studies, partly reported in the present review, have been performed to eliminate inhibitors in environmental and food samples. Inhibiting substances may persist in the extracted sample and can lead to false negative results (Le Guyader et al. 2004a). Moreover, malfunction of the thermal cycler, incorrect PCR mixture, or poor polymerase activity could contribute to false negative results. Hoorfar et al. (2003) underlined that, while false negative results pose a threat for a population, false positive results merely lead to a clarification of presumptive results by retesting the sample. A typical way of revealing false negative RT-PCR results consists of simultaneously analyzing test samples and one sample spiked with the same "target" virus (Fout et al. 2003). While this is an adequate approach, it is expensive and requires extra sample materials and therefore decreases the number of samples available to test within a batch and to test for additional viruses.

Hence, apart from positive and negative detection controls, there is a critical need for sufficient quality controls during the entire food analysis. At least, a process control and an amplification control should be employed.

\section{Process Controls}

The idea of a process control is to spike a sample with a known amount of an agent that possesses similar characteristics of behavior in the food matrices as the virus of interest. The spiking must be done prior to extraction. The level of recovery of such a control will allow the relative quantification of the efficiency of the sample extraction procedure. More important, it will provide data that can assist the interpretation of whether negative results could be false due to failure of the extraction procedure (Le Guyader et al. 2004a).

A process control should comply with the following criteria. Firstly, it should be closely related to the investigated virus, e.g., contain the same nucleotide composition as its genome and, if possible, be a representative of the genus or family of the target virus. Secondly, it should be easily available, simple to standardize, and harmless to work with for the analyzing laboratory. Thirdly, for quantitative testing, it is important that the process control virus is not naturally present in the investigated samples (Hoorfar et al. 2004).

Process controls can be added to the analyzed sample as internal process controls (IPC) or in a parallel sample within the same setup as an external process control. While the use of an IPC is more labor dependent, requiring the addition of extra primers to every sample, it has the advantage of allowing the detection efficiency of every individual test to be determined as this can differ with respect to viral recovery and inhibitor removal if the tissue composition (risk of various amounts of inhibitors) of each sample varies (Hoorfar et al. 2004).

\section{Cultivable Controls}

Closely related to the non-cultivable human NoVs (Duizer et al. 2004a), the family of Caliciviridae includes cultivable animal viruses (with developed RT-PCR primers), which could therefore be used as process controls for the detection of NoVs in food. Among these viruses are the feline calicivirus (FCV) (Sykes et al. 2001; McCann et al. 2003; Bidawid et al. 2003; Helps and Harbour 2003), the canine calicivirus (CaCV) (Hashimoto et al. 1999), and the murine NoV (MNV-1) (Karst et al. 2003; Wobus et al. 2004). To our knowledge, none of these viruses have been detected in food but as NoV surrogates, both FCV and $\mathrm{CaCV}$ have been widely studied during examinations of viral transmission and persistence (Slomka and Appleton 1998; Duizer et al. 2004b). Despite the fact that FCV is more resistant to an acidic environment than $\mathrm{CaCV}, \mathrm{FCV}$ is more susceptible to inactivation than human enteric viruses. Consequently, FCV does not seem to be a suitable surrogate for infectious viruses as a control in processes using acidification steps (Dubois et al. 2006). Nevertheless, FCV may be an option as a process control during $\mathrm{NoV}$ diagnostics in foods. However, the newly cultivable $\mathrm{MNV}-1$ is more closely related to $\mathrm{NoV}$ than both $\mathrm{FCV}$ and $\mathrm{CaCV}$, and therefore it will be interesting to follow future studies to see if this virus shows similar behavior to human $\mathrm{NoV}$.

As a member of the genus Hepatovirus from the family of Picornaviridae, HAV is closely related to the avian encephalomyelitis virus (AEV) (Marvil et al. 1999). This virus exists as a vaccine (Calnek strain) which provides easy access to the strain. Moreover, its sequence is available (GenBank accession number AJ225173), RT-PCR primers have been developed (Todd et al. 1999), and there is no evidence of its presence in food. For these reasons, AEV could be a candidate as a process control for HAV diagnostics. Other Picornaviridae such as poliovirus, which also exist as vaccine strains (killed or attenuated) with developed RT-PCR primers (Fout et al. 2003), have been used as process controls (Le Guyader et al. 2004a; Beuret et al. 2003). However, this virus has been detected in food (Lodder-Verschoor et al. 2005) and can be present as a foodborne pathogen (Lees 2000). Recently, Costafreda et al. (2006) proposed as process control a modified nonpathogenic mengovirus that presents structural characteristics very similar to those of HAV.

\section{Extraction Efficiency}

In several studies of foodborne virus investigations, the extraction efficiency of the applied method has been 
determined by the level of recovery of an added cultivable model virus like enterovirus, FCV, HAV, and MS2 phage (Le Guyader et al. 2004b; Croci et al. 2002; Dubois et al. 2006) in terms of values of plaque forming units (pfu), TCID $_{50}$, or RT-PCR end point titrations per amount of food item. In other studies, the efficiency has been determined as percentage of recovery after spiking with tenfold dilutions of NoV per amount of food (Rzeżutka et al. 2005). As success criteria for satisfactory viral RNA recovery, the detection of a relatively high titer of $\mathrm{NoV}$ added prior to extraction has been used (Beuret et al. 2003; Green et al. 1998). However, using the same virus as both process control and target of investigation poses a risk of false positive results which may arise due to cross contamination during the extraction or amplification process. In a study of a raspberry outbreak, Le Guyader et al. (2004a) used low levels of enterovirus as an IPC and noticed a variation of the extraction efficiency between samples that may have occurred due to inconsistency of tissue composition among samples.

\section{Laboratory Safety}

The risk of infection for laboratory workers has to be considered when human or animal pathogenic viruses are used as controls in the diagnostics. This disadvantage can be overcome by using the Escherichia coli phage MS2 as a target for controlling viral nucleic acid extraction. MS2 phage has an RNA genome, is simple to produce in high yields, and standardization is possible by plating assays to determine pfu. Moreover, stocks of MS2 have shown to be stable for routine use and sensitive TaqMan probes have been developed (Dreier et al. 2005). However, the shortcoming of coliphages as controls for extraction processes in quantitative assays is that they can be naturally present in food items.

Pasloske et al. (1998) describe the development of a versatile, novel system for creating RNase-resistant RNA. "Armored RNA" is a complex of MS2 bacteriophage coat protein and RNA produced in E. coli by the induction of an expression plasmid that encodes the coat protein and an RNA standard sequence. The RNA sequences are completely protected from RNase digestion within the bacteriophage-like complexes. The idea is to introduce such a recombinant MS2 phage as a process control.

\section{Internal Amplification Controls}

Recently, a general guideline for PCR testing that requires the presence of an internal amplification control (IAC) in a reaction mixture has been published by the European Standardization Committee in collaboration with the International Standard Organization (Anonymous 2005). An
IAC is a non-target nucleic acid (NA) sequence present in the same sample reaction tube, which is co-amplified simultaneously with the target sequence (Hoorfar et al. 2004). An endogenous IAC is a template that occurs naturally within the specimen being analyzed. In gene expression analysis and virus screenings of clinical samples, housekeeping genes are often used as IACs and references for transcript quantification (Hennig et al. 2001; Poom et al. 2004), but they have to be proven for any specimens or target. Exogenous IACs are added before nucleic acid amplification (amplification control) where amplification of the IAC can be performed in a second RTPCR or co-amplified within the same reaction as the target. Ideally, these IACs hybridize to the same primers, have identical amplification efficiencies, and contain discriminating features such as length or sequence variations targeted by hybridization probes or TaqMan probes. However, these IACs can lower the amplification efficiency when co-amplified, which results in a lower detection limit of the target virus (Hoorfar et al. 2004). To overcome this, a non-competitive IAC template can be used where the target and IAC are amplified with different primer sets. The disadvantage is that the amplification efficiency of the IAC may not accurately reflect amplification efficiency of the target (Hoorfar et al. 2004).

Different strategies to build RNA-IACs for enteric viruses in food samples were recently described. Among these, Kleiboeker (2003) recommended using two long oligonucleotide primers containing multiple primer binding sites as IAC to synthesize heterologous competitive RNA molecules. Another approach is to construct an IAC derived from the same target virus, distinguishable from the viral amplicon by gel electrophoresis and DNA hybridization depending on the difference in length between the two (Parshionikar et al. 2004).

A RNA-IAC was constructed in two phases to use in a NASBA-based method. In the first phase, a doublestranded DNA fragment that contains non-target sequences flanked by target sequences complementary to the NASBA primers is produced. In the second phase of IAC construction, RNA transcripts are produced from chimeric DNA by T7 polymerase (Rodriguez-Lazaro et al. 2004). So far, only Rzeżutka et al. (2006) have reported the use of an IAC in a PCR-based method for detection of viruses in fruits.

\section{Cell Culture-based Methods}

Although the detection of enteric viruses in food is regularly performed by RT-PCR, there are limitations in RT-PCR for measuring the virological safety of foods since molecular methods do not discriminate between viable infectious virus particles and defective non-infectious virus (Richards 1999). 
Although for several enteric viruses, different cell culture methods have been described (De Medici et al. 2001); no reliable cell culture systems are available for viruses such as HEV and NoV (Duizer et al. 2004a).

Cytopathic effects (CPE) in monolayer cell culture caused by virus-specific killing of infected cells are visible by ordinary light microscopy and allow the presence or absence of infectious virus to be determined. Enumeration of liquid cell culture systems can be done by titration and the calculation of the 'most probable number' or 'tissue culture infectious dose 50 ' $\left(\mathrm{TCID}_{50}\right)$. Besides cell culture in liquid assays, viruses can be cultured in a plaque assay under a solid medium which localizes CPE around the initially infected cell, resulting in the formation of a plaque. By combining cell culture and RT-PCR (cc-RT-PCR), indirect detection of infectivity is obtained, which circumvents the usual long incubation periods for CPE formation (Dubois et al. 2002; O'Mahony et al. 2000; Reynolds et al. 1996) and can also reveal non-cytopathic growth of virus (De Medici et al. 2001). Moreover, many non-cell cultureadapted viruses that circulate in the population and are present in foods are regularly difficult to culture but can be detected by molecular methods without the need of CPE formation.

\section{Various Cell Lines}

Several infectious viruses have been analyzed by cell culture assays for the detection of viruses in fruits and vegetables. Plaque assays (Leggitt and Jaykus 2000) and $\mathrm{TCID}_{50}$ assays (Dubois et al. 2002) have been used for the detection of infectious poliovirus and HAV in seeded lettuce samples by using the African green monkey kidney-derived cell lines BGMK and Vero and a fetal rhesus monkey-derived cell line (FRhK-4). O'Mahony et al. (2000) described a rotavirus plaque assay to study survival of rotavirus following heat and UV irradiation as well as to determine survival in experimentally contaminated foods, including lettuce. To this end, rotaviruses were tissue culture-adapted by propagation in the human colon adenocarcinoma cell line $\mathrm{CaCo}-2$ and the African green monkey kidney cell line MA104 was used to develop a plaque assay. Thus, artificial contamination of foods by seeding of cell culture-adapted viruses such as the rotavirus strain Wa and the HAV strain HM175 and subsequent detection by CPE is a useful tool to study recoveries of concentration methods or virus inactivation.

\section{Problems with Cell Cultures}

However, the analysis of naturally contaminated samples by cell culture assays is extremely difficult, time consuming, and expensive because of the slow, non-cytopathic growth of the majority of viruses. Although detection by integrated cc-RT-PCR circumvents the necessity of CPE formation, it has the potential to detect nucleic acids derived from inactivated virus present in the sample that was inoculated into cell culture (Sobsey et al. 1998). Therefore, Jiang et al. (2004) developed a RT-PCR assay for detection of HAV in water samples that specifically detected negative-stranded HAV RNA. This RNA intermediate is specifically present during replication of the virus, indicating that HAV infection did occur. The same principal was applied by Ko et al. (2003a, b) who developed a RT-PCR assay for detection of infectious adenovirus in water by specific detection of mRNA derived from intracellular replicating adenovirus. Detection of replication intermediates by RTPCR in combination with cell culture could be a reliable tool to detect infectious enteric viruses in foods.

\section{Conclusion and Recommendations}

Because of the inability of several important enteric viruses like NoV to be propagated in cell culture and because of the low infectious dose of enteric viruses and the low concentration of virus in food, the molecular technique of RT-PCR has evolved as the detection method of primary choice. RT-PCR is sensitive and specific, but can easily be inhibited by substances that can be present in the fruit or vegetable matrix. The removal or inactivation of potential inhibitors is a very important step in the methodology (Atmar et al. 1995).

A general outline can be given for virus detection protocols for fresh fruit and vegetables. However, due to the large variations in steps and parameters and the shortage of comparison studies, it is impossible to compose an optimal protocol from the literature. The overall method to extract and detect viruses in foods could be divided into three different steps: (1) virus elution and clarification from substrates, (2) concentration of the viruses, and (3) RNA extraction and purification, amplification, detection of amplified products, and confirmation of the results. Different strategies have been proposed and used to perform these different steps. To come to a standardized horizontal virus detection method for fruit and vegetables, a standard protocol will have to be established for each of the three consecutive steps to form an overall standard method. Given the large differences in composition between soft fruit and hard surface vegetables, it will probably be very difficult, if possible, to select one elution and clarification method of viruses that can be used in all kinds of fruits and vegetables. Several very different methods are used for concentration of viruses eluted from fruit and vegetable matrices. To select a high-yield standard virus concentration method for horizontal use, accurate comparison studies will have to be performed with different fruit and 
vegetable matrices. The virus concentration methods described in this paper could be the methods of choice in such comparison studies.

RNA extraction and purification can be performed using in-house methods, but nowadays often well-standardized and easy-to-use commercially available kits are used. In general, all of these methods are based on the involvement of chemicals such as guanidinium thiocyanate and cetyltrimethylammonium bromide. In contrast to chemical-based processes, generally more efficient immunocapture methods can also be used. The sensitivity and specificity of RT-PCR amplification is highly dependent on the selection of primers and probes. To harmonize this aspect, efforts are made within the CEN/TC275/WG6/TAG4 (virus detection in foods) to standardize RT-PCR protocols, but changes in circulating virus strains will require continuous work on primer selections. At present, real-time PCR is the method of choice, but Europe may need to launch a separate research project to specifically deal with this issue.

Acknowledgements This paper was produced in a co-operative action of the working group on virus detection in foods (WG6/TAG4) of CEN and the FoodPCR2 workpackage (WP10) of the EU MEDVETNET network on foodborne zoonosis.

Open Access This article is distributed under the terms of the Creative Commons Attribution Noncommercial License which permits any noncommercial use, distribution, and reproduction in any medium, provided the original author(s) and source are credited.

\section{References}

Afzal MA, Minor PD (1994) Vaccine 12:976-977

Allwood PB, Malik YS, Maherchandani S, Vought K, Johnson LA, Braymen C, Hedberg CW, Goyal SM (2004) J Food Protection 67:2387

Anonymous (2003) Morb Mortal Wkly Rep 52:1155

Anonymous (2005) (EN ISO 22174) International Organization for Standardisation. Geneva, Switzerland

Atmar RL, Neill FH, Romalde JL, Le Guyader F, Woodley CM, Metcalf TG, Estes MK (1995) Appl Environ Microbiol 61:3014

Berman D, Rohr M, Safferman RS (1980) Appl Environ Microbiol 40:426

Beuret C, Baumgartner A, Schluep J (2003) Appl Environ Microbiol 69:2292

Bidawid S, Farber JM, Sattar SA (2002a) Appl Environ Microbiol 66:2759

Bidawid S, Farber JM, Sattar SA (2000b) J Virol Meth 88:175

Bidawid S, Malik N, Adegbunrin O, Sattar SA, Farber JM (2003) J Virol Meth 107:163

Boom R, Sol CJ, Salimans MM, Jansen CL, Wertheim-van Dillen PM, Van der Noordaa J (1990) J Clin Microbiol 28:495

Butot S, Putallaz T, Sanchez G (2007) Appl Environ Microbiol 73:186

Calder L, Simmons G, Thornley C, Taylor P, Pritchard K, Greening G, Bishop J (2003) Epidemiol Inf 131:745

Cliver D, Ellender RD, Sobsey J (1983) Food Protect 46:345

Cook N (2003) J Microbiol Meth 53:165
Costafreda MI, Bosch A, Pintó RM (2006) Appl Environ Microbiol $72: 3846$

Croci L, De Medici D, Morace G, Fiore A, Scalfaro C, Beneduce F, Toti L (1999) Int J Food Microbiol 48:67

Croci L, De Medici D, Scalfaro C, Fiore A, Divizia M, Donia D, Cosentino AM, Moretti P, Costantini G (2000) J Appl Microbiol 88:293

Croci L, De Medici D, Scalfaro C, Fiore A, Toti L (2002) Int J Food Microbiol 73:29

Dalton CB (1997) Comm Dis Intell 21:321

Dalton CB, Haddix A, Hoffman RE, Mast EE (1996) Arch Intern Med 156:1013

De Leon R, Matsui SM, Baric RS, Herrmann JE, Blacklow NR, Greenberg HB, Sobsey MD (1992) J Clin Microbiol 30:3151

De Medici D, Beneduce F, Fiore A, Scalfaro C, Croci L (1998) Int J Food Microbiol 40:51

De Medici D, Croci L, Di Pasquale S, Fiore A, Toti L (2001) Lett Appl Microbiol 33:362

De Medici D, Croci L, Suffredini E, Toti EL (2004) Appl Environ Microbiol 70:6329

De Serres G, Cromeans TL, Levesque B, Brassard N, Barthe C, Dionne M, Prud'homme H, Paradis D, Shapiro CN, Nainan OV, Margolis HS (1999) J Inf Dis 179:37

Dreier J, Störmer M, Kleesiek KJ (2005) Clin Microbiol 43:4551

Dubois E, Agier C, Traore O, Hennechart C, Merle G, Cruciere C, Laveran H (2002) J Food Prot 65:1962

Dubois E, Hennechart C, Deboosere N, Merle G, Legeay O, Burger C, Le Calve M, Lombard B, Ferre V, Traore O (2006) Int J Food Microbiol 108:164

Duizer E, Schwab KJ, Neill FH, Atmar RL, Koopmans MPG, Estes MK (2004a) J Gen Virol 85:79

Duizer E, Bijkerk P, Rockx B, De Groot A, Twisk F, Koopmans MPG (2004b) Appl Environ Microbiol 70:4538

Falkenhorst G, Krusell L, Lisby M, Madsen SB, Böttiger B, Mølbak K (2005) Eurosurveillance weekly release 10:9. Link: http:// www.eurosurveillance.org/ew/2005/050922.asp\#2

Finance C, Villeval F, Block J, Schwartzbrod L (1981) Appl Environ Microbiol 42:176

Formiga-Cruz M, Hundesa A, Clemente-Casares P, Albinana-Gimenez N, Allard A, Girones R (2005) J Virol Meth 125:111

Fout GS, Martinson BC, Moyer MW, Dahling DR (2003) Appl Environ Microbiol 69:3158

Gilgen M, Germann D, Luthy J, Hubner P (1977) Int J Food Microbiol 37:189

Green J, Henshilwood K, Gallimore CI, Brown DW, Lees DN (1998) Appl Environ Microbiol 64:858

Gulati BR, Allwood PB, Hedberg CW, Goyal SM (2001) J Food Protect 64:1430

Hashimoto M, Roerink F, Tohya Y, Mochizuki MJ (1999) J Vet Med Sci 61:603

Helps C, Harbour DJ (2003) J Virol Meth 109:261

Hennig H, Luhm J, Hartwig D, Kluter H, Kirchner H (2001) Transfusion 41:1100

Hernandez F, Monge R, Jimenez C, Taylor L (1997) Int J Food Microbiol 37:221

Hoorfar J, Cook N, Malorny B, Wagner M, De Medici D, Abdulmawjood A, Fach P (2003) J Clin Microbiol 41:5835

Hoorfar J, Malorney B, Abdulmawjood A, Cook N, Wagner M, Fach P (2004) J Clin Microbiol 42:1863

Jean J, Blais B, Darveau A, Fliss I (2001) Appl Environ Microbiol 67:5593

Jean J, D’Souza DH, Jaykus LA (2004) Appl Environ Microbiol 70:6603

Jiang YJ, Liao GY, Zhao W, Sun MB, Qian Y, Bian CX, Jiang SD (2004) J Appl Microbiol 97:1105

Jiang X, Wang J, Graham DY, Estes MK (1992) J Clin Microbiol 30:2529 
Karst SM, Wobus CE, Lay M, Davidson J, Virgin HW (2003) Science 299:1575

Katzenelson E, Fattal B, Hostovesky T (1976) Appl Environ Microbiol 32:638

Kleiboeker SB (2003) J Clin Microbiol 41:2055

Ko G, Cromeans TL, Sobsey MD (2003a) Appl Environ Microbiol 69:7377

Ko G, Cromeans TL, Sobsey MD (2003b) J Appl Microbiol 69:7377

Kobayashi S, Natori K, Takeda N, Sakae K (2004) Microbiol Immunol 48:201

Koff RS (1998) Lancet 351:1643

Koopmans MPG, Duizer E (2004) Int J Food Microbiol 90:23

Kostenbader KD, Cliver DO (1981) Appl Environ Microbiol 41:318

Kostenbader KD, Cliver DO (1973) Appl Environ Microbiol 26:149

Kreader CA (1996) Appl Environ Microbiol 62:1102

Kurdziel AS, Wilkinson N, Langton S, Cook N (2001) J Food Protect 64:706

Lees DN (2000) Int J Food Microbiol 81:59

Lees DN, Henshilwood K, Green J, Gallimore CI, Brown DW (1995) Appl Environ Microbiol 61:4418

Lodder-Verschoor F, De Roda Husman AM, Van der Berg HHJL, Stein A, Van Pelt-Heerschap HML, Van der Poel WHM (2005) J Food Protect 68:1853

Leggitt PR, Jaykus LA (2000) J Food Protect 63:1738

Le Guyader FS, Dubois E, Menard D, Pommepuy M (1994) Appl Environ Microbiol 60:3665

Le Guyader FS, Haugarreau L, Miossec L, Dubois E, Pommepuy M (2000) Appl Environ Microbiol 66:3241

Le Guyader FS, Mittelholzer C, Haugarreau L, Hedlund KO, Alsterlund R, Pommepuy M, Svensson L (2004a) Int J Food Microbiol 97:179

Le Guyader FS, Schultz AC, Haugarreau L, Croci L, Maunula L, Duizer E, Lodder-Verschoor E, von Bonsdorff $\mathrm{CH}$, Suffredini E, Van der Poel WHM, Reymundo R, Koopmans MPG (2004b) J Food Prot 67:2315

Lewis GD, Metcalf TG (1988) Appl Environ Microbiol 54:1983

Marvil P, Knowles NJ, Mockett APA, Britton P, Brown DK, Cavanagh DJ (1999) J Gen Virol 80:653

Matsumoto K, Hatano M, Kobayashi K, Hasegawa A, Yamazaki S, Nakata S, Chiba S, Kimura Y (1989) J Inf Dis 160:611

McCann KB, Lee A, Wan J, Roginski H, Coventry MJJ (2003) Appl Microbiol 95:1026

Moore C, Clark EM, Gallimore CI, Corden SA, Gray JJ, Westmoreland D (2004) J Clin Virol 29:290

Nishida T, Kimura H, Saitoh M et al (2003) Appl Environ Microbiol 69:5782

O’Mahony J, O’Donoghue MMJG, Hill C (2000) Int J Food Microbiol 61:177

Oron G, Goemans M, Manor Y, Feyen J (1995) Water Res 29:1069
Pasloske BL, Walkerpeach CR, Obermoeller RD, Winkler M, DuBois DB (1998) J Clin Microbiol 36:3590

Parshionikar SU, Cashdollar J, Fout GS (2004) J Virol Meth 121:39

Parry JV, Mortimer PP (1984) J Med Virol 14:277

Pebody RG, Leino T, Ruutu P, Kinnunen L, Davidkin I, Nohynek H, Leinikki P (1998) Epidemiol Inf 120:55

Poom LL, Wong BW, Chan KH, Leung CS, Yuen KY, Guan Y, Peiris JS (2004) J Clin Virol 30:214

Ponka A, Maunula L, von Bonsdorff CH, Lyytikainen O (1999) Epidemiol Inf 123:469

Ramsay CN, Upton PA (1989) Lancet 1:43

Reid TM, Robinson HG (1987) Epidemiol Inf 98:109

Reynolds CA, Gerba CP, Pepper IL (1996) Appl Environ Microbiol 62:1424

Richards GP (1999) J Food Protect 62:691

Rodriguez-Lazaro D, D'Agostino M, Pla M, Cook N (2004) J Clin Microbiol 42:5832

Rosenblum LS, Mirkin IR, Allen DT, Safford S, Hadler SC (1990) Am J Publ Health 80:1075

Rutjes SA, Italiaander R, Van den Berg HHJL, Lodder WJ, De Roda Husman AM (2005) Appl Environ Microbiol 71:3734

Rutjes SA, Lodder-Verschoor F, Van der Poel WHM, Van Duynhoven YTHP, De Roda Husman AM (2006) J Food Protect 69:1949

Rzeżutka A, Alotaibi M, D’Agostino M, Cook N (2005) J Food Protect 68:1923

Rzeżutka A, D’Agostino M, Cook N (2006) Int J Food Microbiol 108:315

Sair AI, D'Souza DH, Moe CL, Jaykus LA (2002) J Virol Meth 100:57

Sadovski AY, Fattal B, Goldberg D, Katzenelson E, Shuval HI (1978) Appl Environ Microbiol 36:824

Schwab KJ, Neill FH, Fankhauser RL et al (2000) Appl Environ Microbiol 66:213

Seymour IJ, Appleton H (2001) J Appl Microbiol 91:759

Slomka MJ, Appleton H (1998) Epidemiol Inf 121:401

Sobsey MD, Battigelli DA, Shin GA, Newland S (1998) Water Sci Tech 38:91

Steele M, Odumeru J (2004) J Food Protect 67:2839

Straub TM, Pepper IL, Gerba CP (1994) Can J Microbiol 40:884

Svensson L (2000) Int J Food Microbiol 59:117

Sykes JE, Allen JL, Studdert VP, Browning GF (2001) Vet Microbiol 81:95

Tei S, Kitajima N, Takakashi K, Mishiro S (2003) Lancet 362:371

Todd D, Weston JH, Mawhinney KA, Laird C (1999) Avian Dis 43:219

Vinjé J, Vennema H, Maunula L et al (2003) J Clin Microbiol 41:1423

Wang MJ, Moran GJ (2004) Ann Emerg Med 43:660-662 discussion 662

Ward BK, Chenoweth CM, Irving LG (1982) Appl Environ Microbiol 44:1389

Wilde J, Eiden J, Yolken R (1990) J Appl Microbiol 28:1300

Wobus CE, Karst SM, Thackray LB et al (2004) PLoS Biology 2:e432 